\title{
ANALISIS INVESTIGASI ANDROID FORENSIK SHORT MESSAGE SERVICE (SMS) PADA SMARTPHONE
}

\author{
Mitra Unik' ${ }^{1)}$, Vicky Gema Larenda ${ }^{2)}$ \\ 1,2, Fakultas Ilmu Komputer, Universitas Muhammadiyah Riau \\ email : mitraunik@umri.ac.id, larendavicky@student.umri.ac.id, harunmukhtar@umri.ac.id
}

\begin{abstract}
Mobile devices (Smartphones) are important domains in communication. Short Message Service (SMS) is a service that can be used to send short messages in the form of text. Most modern cellphones (smartphones) store SMS in internal memory, not on a SIM card so that in the acquisition process requires material on the SMS. The purpose of this study is to explain the process of implementing digital evidence on the material examining the SMS on a Smartphone, so that it can become legitimate digital evidence. Furthermore, this research is also to get traces of digital communication on Smartphone evidence. This study uses forensic methods that can really support the data or information obtained. On smartphones, all activities of messages are stored and processed in the database. The database for SMS is found in folderdata / com.android.providers.telephony / database found. For sms files stored in mmssms.db, which is in the database sub folder. Review the location using a forensic tool capable of finding and extracting incoming and outgoing messages, the metadata of the mmssms.db file contains the md5 hash value, capacity file, creation (created), access time (accessed), modified transmission ), change time (changed). Furthermore in this study, a search to rediscover the message that was successfully carried out.
\end{abstract}

Keywords: Digital Forensic, SMS, Smartphone, Digital Evidence.

\begin{abstract}
Abstrak
Perangkat seluler (Smartphone) menjadi domain penting dalam berkomunikasi. Layanan Pesan Singkat (SMS) adalah layanan yang dapat digunakan utnuk mengirim pesan singkat berupa teks. Sebagian besar ponsel modern (smartphone) menyimpan SMS dalam memori internal, bukan pada kartu SIM sehingga dalam proses akuisisi kasus yang melibatkan materi pada SMS. Tujuan dari penelitian ini yakni menjelaskan proses penanganan bukti digital pada materi periksa yaitu SMS pada Smartphone, sehingga dapat menjadi barang bukti digital yang sah. Selanjutnya Penelitian ini juga untuk mendapatkan jejak - jejak digital komunikasi sms pada barang bukti Smartphone. Penelitian ini menunjukkan penggunaan metode forensik yang benar dapat menjaga integrasi data atau informasi yang diperoleh. Pada smartphone, seluruh aktivitas dari pesan disimpan dan diproses dalam database. Database untuk sms terdapat dalam ditemukan folderdata/com.android.providers.telephony/databases. Untuk file sms tersebut tersimpan pada mmssms. $d b$ yang terdapat didalam sub folder databases. Akuisis pada lokasi tersebut dengan menggunakan tool forensik mampu menemukan dan mengektraksi pesan masuk maupun pesan keluar yang terengkripsi, Metadata dari file mmssms.db berisikan nilai hash md5, kapasitas file, waktu pembuatan (created), waktu akses (accessed), waktu modifikasi (modified), waktu perubahan (changed). Selanjutnya pada penelitian ini pencarian untuk menemukan kembali pesan SMS yang telah dihapus berhasil dilakukan.
\end{abstract}

Kata Kunci : Digital Forensik, SMS, Smartphone, Bukti Digital

\section{PENDAHULUAN}

Insiden dunia maya berlangsung sangat cepat dan meningkat dalam jumlah dan korban, ketika insiden dunia maya terjadi, orang-orang yang diserang atau menjadi korban merespon dengan serangkaian tindakan yang telah ditentukan (ISACA 2015). Bidang forensik digital dimulai pada pertengahan 1980-an dengan pemahaman dari beberapa lembaga penegak hukum bahwa komputer akan memainkan peran penting dalam penyelidikan future criminal (Gentry 2019). 
Menerapkan keilmuan forensik digital untuk membantu dalam pemulihan dan penyelidikan materi pada media digital dan jaringan komunikasi adalah tindakan yang biasa dilakukan (Unik 2015). Ada banyak jenis media digital dan perangkat pengguna akhir, yang mungkin ditemui selama pencarian di tempat kejadian, yang semuanya memiliki potensi untuk menyimpan data yang mungkin bernilai bagi penyelidikan. Proses mengidentifikasi, melestarikan, menganalisis dan menyajikan bukti digital dengan cara yang tepat dapat diterima secara hukum dalam setiap proses hukum (yaitu, peradilan) (Kent et al. 2006). Digital Forensik mempunyai banyak cabang salah satunya adalah Mobile Forensik. Mobile Forensik adalah ilmu untuk memulihkan bukti digital dari perangkat mobile dibawah kondisi forensik menggunakan metode yang diterima (Butterfield et al. 2007).

Indonesia berada di urutan ke-24 dari 27 negara terbanyak yang menggunakan Mobile smartphone (Yanuar 2019). Tipe - tipe yang termasuk kedalam Mobile Forensik adalah sebagai berikut (Martin 2008), yaitu : Cellular Phone, Smart Phone, dan Mp3 Player

Barang bukti pada forensik digital bersifat fisik dan dapat dikenali secara visual, sehingga investigator dan analisis forensik harus sudah memahami serta mengenali masing - masing barang bukti elektronik ini ketika sedang melakukan proses pencarian (Searching) barang bukti di TKP (Al-Azhar 2012).

Short Message Service (SMS) Merupakan sebuah teknologi yang menyediakan pelayanan pengiriman dan penerimaan pesan antar ponsel. SMS pertama kali diperkenalkan di Eropa sekitar tahun 1992, yang pertama kali terintegrasi dengan GSM (Global System for Mobile Communications) yang kemudian berkembang dalam CDMA dan TDMA (Sunardi, Hari Murti 2014).

Tujuan dari penelitian ini adalah menjelaskan proses penanganan bukti digital berupa Smartphone sehingga dapat menjadi barang bukti digital yang sah. Penelitian ini juga untuk mendapatkan jejak - jejak digital komunikasi sms pada barang bukti Smartphone.

\section{METODE PENELITIAN}

Metode proses investigasi ditetapkan sebagai pross linear dari Prepartion hingga Laporan.

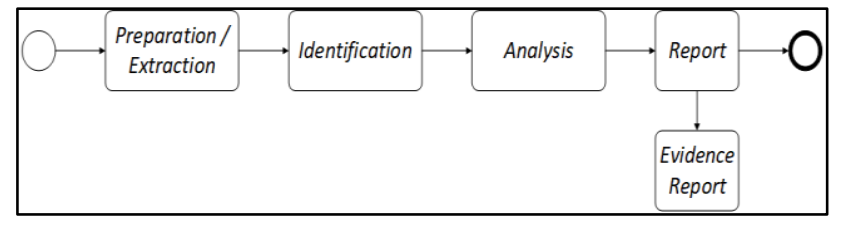

Gambar 1. Metode Investigasi Digital Forensik Sumber: (DFRWS 2001)

a. Preparation/Extraction

Pada proses persiapan barang bukti dan ektraksi ini melibatkan proses dan cara yang digunakan sesuai dengan perangkat yang akan diperiksa.

b. Identification

Pada tahap ini merupakan tahapan untuk mengidentifikasi keseluruhan barang bukti, terkait dengan relevansi barang bukti tersebut terhadap studi kasus.

c. Analysis

Proses ini melakukan pencarian yang mendalam untuk barang bukti fisik, mengembangkan teori berdasarkan hasil analisis dan pengujian terhadap barang bukti.

d. Report

Proses ini merupakan tahap akhir dari proses digital forensik, dalam proses ini memaparkan hasil analisis dari barang bukti kedalam form khusus.

\section{HASIL DAN PEMBAHASAN}

\subsection{Preparation / Extraction}

a. Identifikasi barang bukti

Untuk identifikasi barang bukti smartphone, pada penelitian ini menggunakan Smartphone Android yang diperoleh dalam kondisi fisik baik. Untuk akuisisi objek penelitian ini diakuisisi dalam keadaan menyala / hidup (on).

b. Proses akuisisi bukti digital

Proses akuisi diikat dalam sebuah prosedur dan aturan yang berlaku, sesuai dengan prinsipprinsip investigasi (ACPO 2012) : 


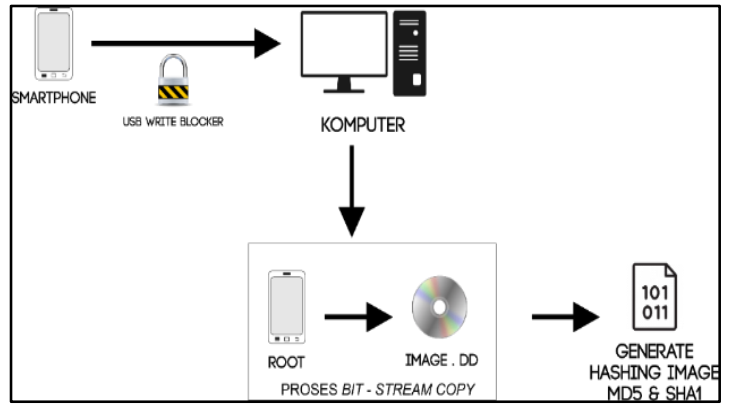

Gambar 2. Proses Akuisisi Bukti Digital Smartphone

Pada gambar 6 merupakan proses akuisisi bukti digital smartphone. Proses yang ada meliputi :

1. Menggunakan USB Write Blocker untuk melindungi keaslian objek penelitian

2. Menghubungkan smartphone ke komputer menggunakan kabel USB

3. Mengaktifkan usb debugging mode untuk melakukan proses root pada smartphone

4. Melakukan root pada smartphone dengan menggunakan tool KingoRoot dan BusyBox

5. Setelah proses root selesai, melakukan imaging pada smartphone dengan menggunakan teknik imaging bit-stream copy dan menghasilkan file image dengan file ekstensi (.dd).

6. Melakukan generate hashing MD5 dan SHA1 menggunakan tool AccessData FTK Imager pada file image sebagai nilai hash dari smartphone.

\subsection{Identifikasi}

Pada pesan sms, seluruh aktivitas dari pesan disimpan dan diproses dalam database. Database untuk sms terdapat dalam folderdata/com.android.providers.telephony/d atabases. Database sms ini terletak pada folder "com.android.providers.telephony"/ "database $s$ ". merupakan struktur dari com.android.providers.telephony.

\subsection{Analisis}

Dalam penelitian ini komponen dasar investigasi penulis lakukan guna memastikan bahwa data tersebut sama validnya dengan yang asli. (Agarwal and Gupta 2011).

a. Mencari Database dari Pesan SMS

Database dari pesan sms terdapat pada folder com.android. providers. telephony. Pada folder com.android. providers. telephony terdapat 2 subfolder yaitu shared_pref dan databases. Untuk file sms tersebut tersimpan pada mmssms.db yang terdapat didalam sub folder databases.

Saat file mmssms.db dibuka pada tool Autopsy, dapat dilihat metadata dari mmssms. $d b$ berikut ini:

Tabel 1. Metadata File mmssms.db

\begin{tabular}{|l|l|}
\hline Name & $\begin{array}{l}\text { /img_bbandroidoppor815.dd/vol_vol } \\
\text { 13/data/com.android.providers.teleph } \\
\text { ony/databases/mmssms.db }\end{array}$ \\
\hline Type & File System \\
\hline MIME Type & application/x-sqlite3 \\
\hline Size & 172032 \\
\hline $\begin{array}{l}\text { File Name } \\
\text { Allocation }\end{array}$ & Allocated \\
\hline $\begin{array}{l}\text { Metadata } \\
\text { Allocation }\end{array}$ & Allocated \\
\hline Modified & $2018-05-0313: 56: 26$ ICT \\
\hline Accessed & $2013-01-01$ 19:02:23 ICT \\
\hline Created & $2013-01-01$ 19:02:23 ICT \\
\hline Changed & $2018-05-0313: 56: 26$ ICT \\
\hline MD5 & a5779f5757af1d7bb3ad52f0a04367f3 \\
\hline $\begin{array}{l}\text { Hash lookup } \\
\text { Result }\end{array}$ & UNKNOWN \\
\hline Intenal ID & 6945 \\
\hline
\end{tabular}

Terlihat bahwa Pesan di modifikasi terakhir pada tanggal 3 Mei 2018 pada pukul 13:56:26 ICT. Pada bagian tabulasi hex ditemukan pesan yang dihapus.

b. Mencari pesan sms yang ada pada file mmssms.db

Pesan sms ditemukan dan untuk pesan yang pertama dari urutan atas ke bawah merupakan sms yang terakhir kali dilakukan baik itu sms diterima maupun sms dikirim. Pada data mmssms.db pesan tersebut terdapat pada baris 0000A390.

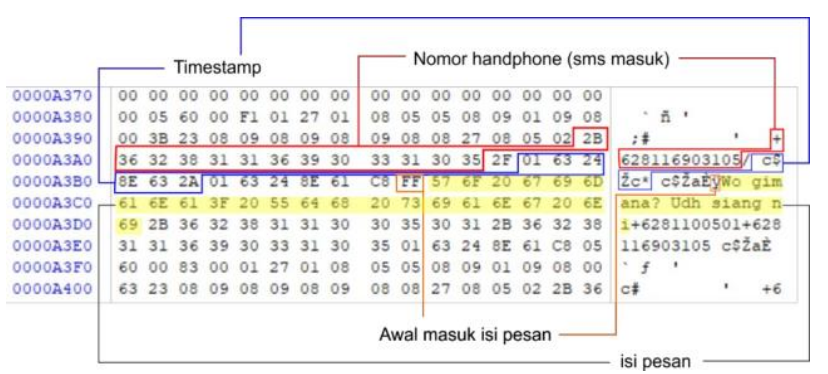

Gambar 3. Informasi pesan SMS Masuk

Pada gambar diatas dapat dilihat Pada nomor handphone pertama merupakan pesan sms masuk, karena ditandai dengan nilai +62(nomor kode wilayah Indonesia). 
Sedangkan kode unik setelahnya merupakan timestamp (waktu) dari pesan sms masuk tersebut. Untuk awal masuknya pada isi pesan, kode hex ditandai dengan nilai $\mathrm{F}$ yang menandakan bahwa isi pesan dimulai.

Untuk konversi kode hex ke decimal dilakukan menggunakan konversi secara online pada website

https://www.binaryhexconverter.com/hextodec imalconverter, sehingga dihasilkan nilai decimal, sedangkan untuk konversi nilai decimal tersebut ke Epoch Time menggunakan konversi secara online pada website https://www.epochconverter.com/.EpochTime tersebut nilai waktu yang bisa dibaca oleh manusia yang dapat dilihat pada tabel 2 berikut ini :

Tabel 2. Konversi Timestamp

\begin{tabular}{|c|c|c|c|}
\hline $\begin{array}{l}\text { Hexadec } \\
\text { imal }\end{array}$ & Decimal & $\begin{array}{l}\text { Unix Epoch } \\
\text { Time }\end{array}$ & $\begin{array}{l}\text { Waktu } \\
\text { Indonesia } \\
\text { Barat }\end{array}$ \\
\hline $\begin{array}{l}0163248 \\
\text { E632A }\end{array}$ & $\begin{array}{l}152532670 \\
1354\end{array}$ & $\begin{array}{l}\text { Thursday, } \\
\text { May 3, } 2018 \\
5: 51: 41.354 \\
\text { AM (GMT } \\
+0)\end{array}$ & $\begin{array}{l}\text { Rabu I } \\
\text { Thursday } \\
\text { 3 Mei } \\
2018 \\
\text { 12:51:41. } \\
\text { 354 PM }\end{array}$ \\
\hline
\end{tabular}

Pada tabel tersebut terlihat bahwa waktu dari kode hexadecimal diatas adalah Rabu, 3 Mei 2018 12:51:41.354 PM. Untuk pesan sms yang keluar, pada kode ASCII nomor handphone tujuan yang digunakan tidak langsung menggunakan kode wilayah (kode wilayah Indonesia adalah +62 ), namun langsung nomor handphone tersebut yakni 08116903105

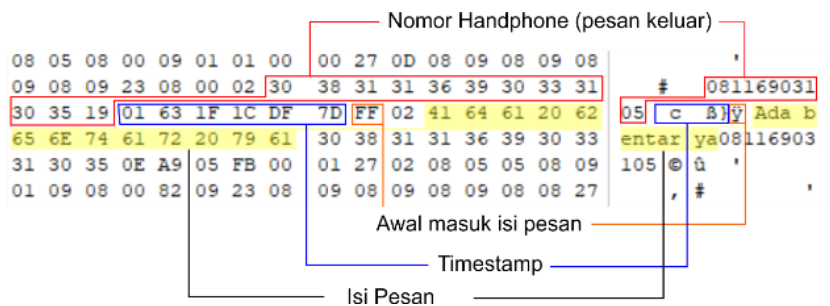

Gambar 4. Informasi pesan SMS Keluar

c. Membaca pesan serta menampilkan artefak - artefak yang berkaitan dengan sms

Pembacaan pesan dan pengambilan artefak atau jejak dapat dilakukan dengan tool oxygen Forensic SQLite Viewer seperti yang penulis lakukan. Untuk itu maka file mmssms.db dibuka pada tool Oxygen Forensic SQLite Viewer.

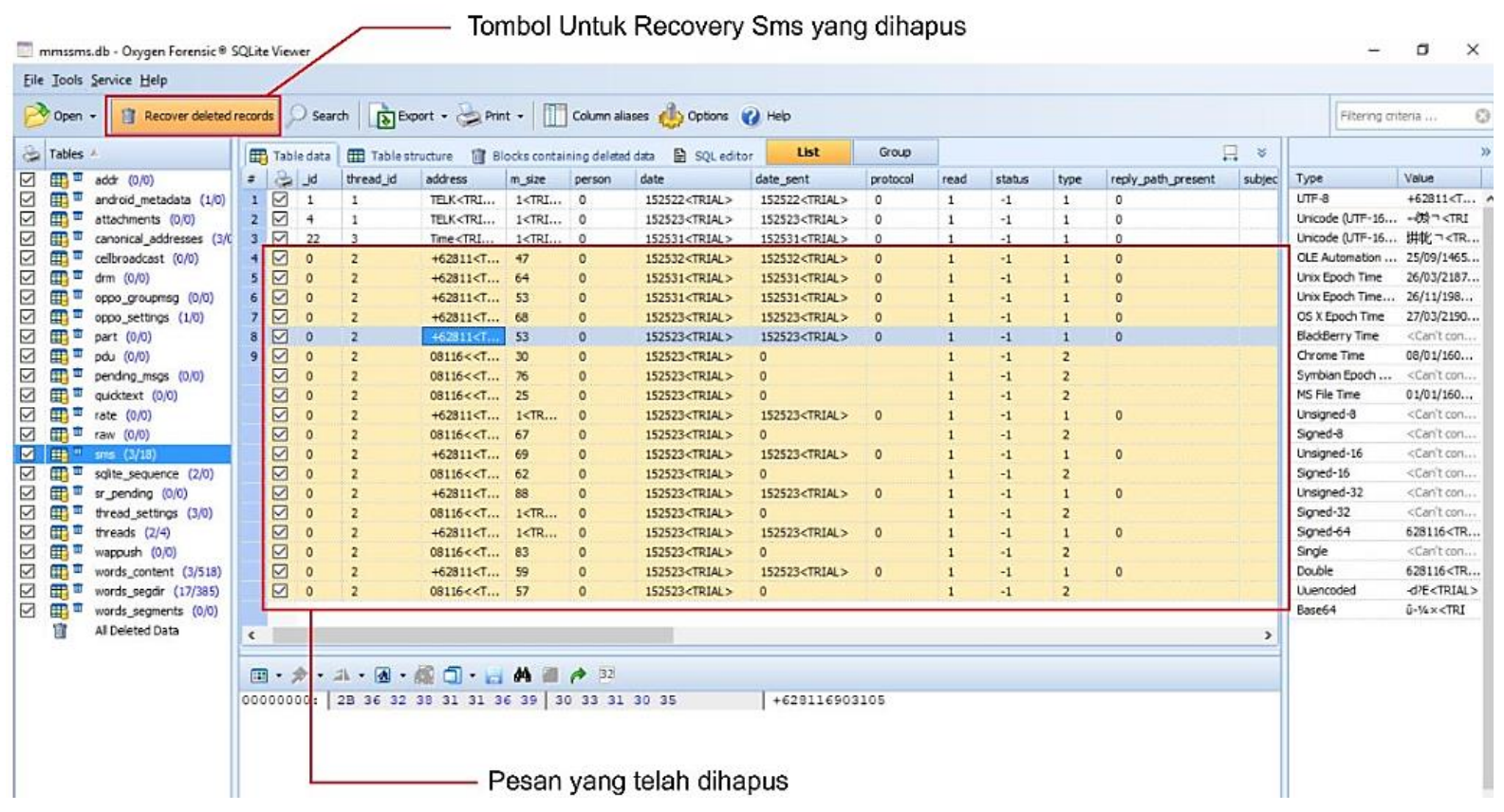

Gambar 5. Recovery Pesan SMS yang Sudah Dihapus 
Gambar diatas dapat dilihat bahwa isi dari record sms yang dihapus dimunculkan kembali. Pada beberapa kolom di tabel ada sebagian yang disembunyikan (hidden) nilainya dikarenakan tool Oxygen Forensic SQLite Viewer ini masih menggunakan lisensi trial (Percobaan). Namun jika di klik pada kolom tertentu, pada tampilan layar bawah akan menampilkan seluruh isi dari bagian tersebut.

\subsection{Skup hasil akuisisi}

Masing - masing pesan sms tersebut terdapat perbedaan. Untuk pesan yang dikirim (pelaku), nomor handphonenya tanpa diawali dengan nomor kode wilayah Indonesia (+62). Sedangkan pesan yang masuk (korban) menggunakan kode wilayah Indonesia (+62). Hasil akuisis serta keterangan informasi yang didapat penulis sajikan dalam tabel yang memperlihatkan hasil string dan code Hex dari hasil akuisisi.

\begin{tabular}{|c|c|}
\hline & \\
\hline \multirow[t]{2}{*}{1} & 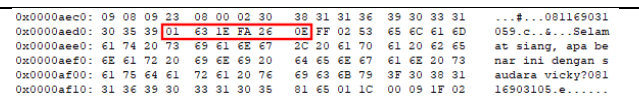 \\
\hline & $\begin{array}{l}\text { Pelaku : Selamat siang, apa benar ini } \\
\text { dengan saudara vicky? } \\
\text { Timestamp : } 0163 \text { 1E FA } 26 \text { 0E (Hex), } \\
\text { Wednesday-May 2, } 2018 \text { 10:51:40.302 } \\
\text { am (GMT+7) }\end{array}$ \\
\hline \multirow[t]{2}{*}{2} & 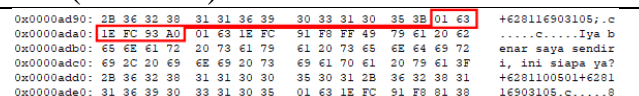 \\
\hline & $\begin{array}{l}\text { Korban : Iya benar saya sendiri, ini siapa } \\
\text { ya? } \\
\text { Timestamp : } 0163 \text { 1E FC } 93 \text { A0 (Hex), } \\
\text { Wednesday-May 2, } 2018 \text { 10:54:19.424 } \\
\text { am (GMT+7) }\end{array}$ \\
\hline \multirow[t]{4}{*}{3} & 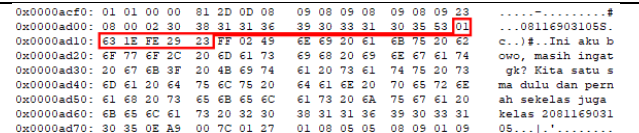 \\
\hline & $\begin{array}{l}\text { Pelaku : Ini aku bowo, masih ingat gk? } \\
\text { Kita satu sma dulu dan pernah sekelas } \\
\text { juga kelas } 2\end{array}$ \\
\hline & $\begin{array}{l}\text { Timestamp : } 0163 \text { 1E FE } 2923 \text { (Hex), } \\
\text { Wednesday - May 2, } 2018 \text { 10:56:03.235 } \\
\text { am (GMT+7) }\end{array}$ \\
\hline & Selanjutnya... \\
\hline
\end{tabular}

Dari tabel tersebut dapat terlihat pesan sms yang dihapus didapatkan pesan nomor handphone, timestamp, serta isi dari pesan yang dihapus. Untuk kode hex yang ditandai merupakan timestamp dari pesan tersebut. Pembeda antara si pelaku dengan korban adalah awal dari nomor handphone tersebut. Jika nomor handphone tersebut diawali dengan nomor kode wilayah Indonesia yaitu +62 maka pesan tersebut merupakan pesan masuk (korban), sedangkan jika nomor tersebut tidak diawali dengan +62 maka pesan tersebut merupakan pesan yang dikirim (pelaku) dari smartphone tersebut. Untuk kode hex yang ditandai merupakan timestamp dari pesan tersebut. Kode hex tersebut dikonversi ke bilangan desimal lalu dikonversi kembali ke kode UNIX Epoch time untuk dapat dibaca namun masih dalam waktu GMT + 0, maka dikonversi kembali ke dalam waktu Indonesia yaitu GMT+7. Kode hex tersebut dikonversi ke bilangan desimal lalu dikonversi kembali ke kode UNIX Epoch time untuk dapat dibaca namun masih dalam waktu GMT + 0, maka dikonversi kembali ke dalam waktu Indonesia yaitu GMT+ 7.

\section{SIMPULAN}

Atas hasil penelitian ini maka diperoleh kesimpulan sebagai berikut :

1. Informasi (SMS) berhasil didapatkan dari investigasi forensik pada rankaian pencarian dan pengujian Barang bukti di penelitian ini.

2. Barang bukti berhasil didapatkan dari investigasi forensik pada kasus penipuan sms berupa nilai hashing md5 dan sha1 dari barang bukti sms yang ditemukan yaitu pada file mmssms.db. metadata dari file mmssms.db berisikan nilai hash $\mathrm{md} 5$, kapasitas file, waktu pembuatan (created), waktu akses (accessed), waktu modifikasi (modified), waktu perubahan (changed).

3. Hasil pencarian untuk menemukan kembali pesan SMS yang telah dihapus berhasil dilakukan.

\section{UCAPAN TERIMAKASIH}

Alhamdulillah kehadirat Allah SWT serta penulis ucapkan kepada seluruh orang-orang yang telah membantu dalam penyusunan penelitian ini.

\section{DAFTAR PUSTAKA}

ACPO. 2012. ACPO Good Practice Guide for Digital Evidence.

Agarwal, A, and M Gupta. 2011. "Systematic Digital Forensic Investigation Model." ... Journal of Computer ... 5(1): 118-31. 
Al-Azhar, Muhammad Nuh. 2012. Digital Forensic, Panduan Praktis Investigasi Komputer. ed. Palupi Wuriarti. Jakarta: Salemba Infotek.

Butterfield, Jason, Miles Tracy, Wayne Jansen, and Scarfone Karen. 2007. "Guidelines on Electronic Mail Security Recommendations of the National Institute of Standards and Technology." : 139.

DFRWS. 2001. "A Road Map for Digital Forensic Research." In The Digital Forensic Research Conference, Utica: dfrws.org.

Gentry, Eric Elwood. 2019. "SEAKER: A Mobile Digital Forensic Triage Device By." University Channel Islands. https://prof.msoltys.com/wpcontent/uploads/2019/04/SEAKER_Thes is.pdf.

ISACA. 2015. "Overview of Digital Forensics." isaca.org.

Kent, Karen, Chevalier Suzanne, Tim Grance, and Hung Dang. 2006. Guide to Integrating Forensic Techniques into Incident Response. Gaithersburg, Maryland.

Martin, Andrew. 2008. SANS Instituted InfoSec Reading Room, Mobile Device Forensics.

Sunardi, Hari Murti, Hersatoto Listiyono. 2014. "Aplikasi SMS Gateway." Jurnal Teknologi Informasi DINAMIK XIV(1): 30-34.

Unik, Mitra. 2015. "Analisis Investigasi Dan Perancangan Kerangka Kerja Forensika Digital Pada Mesin Fotokopi Multi Function Peripheral (Mfp)." UNIVERSITAS ISLAM INDONESIA.

Yanuar, Yudono. 2019. "Survei Kepemilikan Smartphone, Indonesia Peringkat Ke-24." Tempo.co. https://tekno.tempo.co/read/1181645/sur vei-kepemilikan-smartphone-indonesiaperingkat-ke-24/full\&view=ok (July 3, 2019). 